\title{
Perception of Online Learning among Undergraduate Students at Suez Canal Medical School during the COVID-19 Pandemic: A Cross-Sectional Study
}

Noha M Abu Bakr Elsaid ${ }^{1}$, Hadeer El Nagar ${ }^{1}$, Doaa Kamal*2 ${ }^{2}$, Mariam Yousef Bayoumi ${ }^{3}$, Monica George Kamel $^{3}$, Ahmed Adel Abuzeid ${ }^{3}$, Sara Abdelrahman Elewa ${ }^{3}$, Menna Mohamed Hussein ${ }^{3}$, Hussein Nasser

Hussein $^{3}$, Ahmed Mohamed Saed Elshahidy ${ }^{3}$, Jawad Abdelnasser Saleh ${ }^{3}$

${ }^{1}$ Department of Public Health, Community, Occupational and Environmental Medicine,

${ }^{2}$ Department of Medical Education, ${ }^{3}$ Fifth Year Medical Student,

Faculty of Medicine, Suez Canal University, Egypt.

*Corresponding author: Doaa Kamal, Mobile: $(+20) 01222486807$,

E-mail: doaa_kamal@med.suez.edu.eg,dr_doaa84@yahoo.com

\begin{abstract}
Background: Many adaptations to medical education have been made in response to the new emergent COVID-19 pandemic and its enormous global effects including the teaching and learning strategies to assure the educational process's safety and advancement. Accordingly, it was necessary to implement new online instructional approaches at the Faculty of Medicine, Suez Canal University in Egypt.

Objective: To assess online learning advantages and disadvantages as perceived by medical students in addition to their preference regarding online vs face-to-face learning,

Subjects and methods: This study was conducted as a cross-sectional study that included 340 students who filled an online survey consisting of 16 questions and was conducted on the Google Forms platform. Target population: years 1, 2 and 3 undergraduate medical students at Faculty of Medicine, Suez Canal University who experienced online learning during the COVID-19 pandemic.

Results: The mean age of students was $19.57 \pm 1.02$, ranged from 17 to 23 years, $61 \%$ of them were females. About $63.8 \%$ of students had no previous experience with online learning. The main perceived advantages were the ability to stay home $(63.8 \%)$, comfortable surrounding $(52.1 \%)$ and access to online materials $(47.1 \%)$, while the main perceived disadvantages were technical problems (67.6\%), lack of interaction with patients $(58.8 \%)$, and reduced interaction with teachers $(48.5 \%)$. Most of the students found face-to-face learning is superior to online learning in improving the knowledge $(\mathrm{p}=0.005)$, clinical skills $(\mathrm{p}<0.001)$ and social competence $(\mathrm{p}<0.001)$. Though $77 \%$ of them rated online learning as enjoyable.

Conclusion: Most of our participants preferred traditional face-to-face learning over the online learning. Stakeholders should take the required steps to improve learning by reducing the disadvantages and increasing advantages of online learning as perceived by students during this study.
\end{abstract}

Keywords: COVID-19, Egypt, Online Learning, Perception.

\section{INTRODUCTION}

The use of a wide range of technologies such as the internet, email, chat, new groups and texts, audio and video conferencing transmitted across electronic networks to transfer education is referred as online learning. It enables students to study at their own speed and at their own convenience. It usually necessitates meticulous planning and a significant investment of time and money ${ }^{(\mathbf{1})}$.

Online distance learning enabled educators/tutors to overcome some of the limitations of face-to-face teaching by allowing easier communication and interaction between tutors and students. Besides the ability to provide immediate educational support and feedback gives, online learning has many logistical, instructional and financial advantages over face-to-face teaching ${ }^{(2)}$.

Many educators may find online learning a useful tool to scaffold learning, through providing a common set of learning resources and experiences as well as through enabling group discussion without the need for teacher and learners to be physically present or working at the same time. Various novel online venues provide useful learning spaces for students and tutors who might find it difficult to meet together in real time ${ }^{(3)}$.

Among the success factors of online learning is the used delivery technology improves learning. It has been recognized that specialized delivery technology can provide efficient and timely access to learning material. However, researches claim that used technologies are only vehicles that deliver instructions, and do not themselves improve student achievement, they suggest that the used instructional strategies and content influence student learning more than the type of technology used to deliver instruction ${ }^{(4)}$.

Online learning encourages learners to be selfdirected learners and to improve their own skills of self-organization in addition to skills in technology ${ }^{(5)}$. At institutional level; online learning can also potentially sustain educational programs that have been struggling for many reasons in an on-campus version 
including increased students' number and economic pressures ${ }^{(6)}$.

Despite the effectiveness of online learning, researches reveal that it couldn't replace the traditional face-to-face learning particularly for the affective domain (such as: face-to-face personal relationship; affection, imitation work), as it provides students and educators with real and substantive contact. Also, there is little guidance on how to integrate online learning into the curriculum. Unfortunately, the use of technology presents challenges to both learners and facilitators ${ }^{(7)}$

Among the potential limitations of online learning are the need for proper and stable financial support, adequate time, organizational and staff members preparedness, student readiness, crisis management, resistance to change, technical support, synchronous/ asynchronous-classroom contexts, delayed feedback, and evaluation and assessment ${ }^{\left({ }^{6}\right)}$.

Before considering applying online learning practices, full evaluation is an essential need. An important part of such evaluation is the consideration of pros and cons of using such learning modalities. This consideration is important as it serves as the basis for various future decisions ${ }^{(8)}$. The importance of considering these logistical components of online learning, suggesting that improperly functioning technology and implementation plan may affect learning and students/staff engagement that will eventually be frustrating for students and decrease their overall satisfaction ${ }^{(9)}$.

Because of the urgent need for a paradigm shift to online learning in all medical institutions during the COVID-19 pandemic, there was a need to explore undergraduate student perception regarding online learning as a new learning at Faculty of Medicine- Suez Canal University (FOM-SCU). The findings may help to provide evidence about advantages and disadvantages of this paradigm shift that would eventually allow better understanding and future improvement of online learning.

\section{Research Objectives:}

Primary objectives: To identify advantages and disadvantages of online learning as perceived by undergraduate medical students at FOM-SCU. To assess undergraduate medical students at FOM-SCU satisfaction regarding online learning experience during COVID-19 pandemic.

Secondary objectives: To determine whether students prefer online learning over traditional face-to-face learning.

\section{SUBJECTS AND METHODS}

Research design: A cross-sectional descriptive study.

Research setting: This research was conducted at the Faculty of Medicine, Suez Canal University (FOM$\mathrm{SCU})$ in Ismailia, Egypt.
Research subjects: Target population: years 1,2 and 3 undergraduate medical students at FOM-SCU who experienced online learning during the COVID-19 pandemic.

\section{Sample size:}

According to the $77.4 \%$ percentage of students who have an unfavorable attitude towards online learning (10), sample size was calculated to be 269 students. After the addition of $10 \%$ non-response rate, the sample size was 296 students, but we received responses from 340 students.

\section{Sampling method:}

The sample was selected as a stratified random sample. The selected students were divided into two strata based on their learning phase. The academic strata, which included $1^{\text {st }}$ and $2^{\text {nd }}$ year medical students and the clinical strata, which included third year medical students. A list of students' names in academic and clinical phases was obtained then students were selected randomly by proportionate method until required sample size was reached.

The Clinical phase represented $40 \%$ of the sample size, while the academic phase represented $60 \%$ of the sample size according to total count of the students in the first three years at FOM-SCU.

\section{Ethical consideration:}

This study was approved by the Research Ethics Committee of Faculty of Medicine, Suez Canal University on 20-1-2021 with approval No: 4450.

Permissions to collect data were obtained from the Faculty of Medicine, Suez Canal University administration. The response of subjects was voluntary, as they could refuse to respond without stating any reason. Subjects were told that their information confidentiality was kept.

Informed consent was written in the front part of the Google Form. This work has been carried out in accordance with The Code of Ethics of the World Medical Association (Declaration of Helsinki) for studies involving humans.

\section{Data collection tool:}

Data was collected in the period from January to March, 2021 by using a structured online questionnaire on Google forms. The questionnaire was used in a previous study and available in English language ${ }^{(11)}$.

The questionnaire was sent to medical education experts for content validity and piloted on 34 students (who were excluded from the analysis) to investigate its reliability. The questionnaire consisted of the following four sections:

1) Basic sociodemographic characteristics of the study participants such as age, gender and medical year. 
2) Perceived advantages and disadvantages of online learning. Each part was assessed by six items. Multiple responses were allowed, so student could choose more than one response.

3) Using a five-grade Likert scale ranging from one to five (1=absolutely ineffective, 5=absolutely effective) to compare face-to-face and online learning in terms of ability to meet learning objectives: knowledge, clinical skills, and social competences.

4) Acceptance of online learning by using five grade Likert scale ranging from 1 to 5 (1= Extremely unenjoyable, 5= Extremely enjoyable).

Questionnaire was available at this link: https://forms.gle/niKEw2JiEKYpwvT78

\section{Statistical analysis}

The collected data were coded, processed and analyzed using the SPSS (Statistical Package for the Social Sciences) version 22 for Windows ${ }^{\circledR}$ (IBM SPSS Inc, Chicago, IL, USA). Data were tested for normal distribution using the Shapiro Wilk test. Qualitative data were represented as frequencies and relative percentages and were calculated by Chi square test $\left(\chi^{2}\right)$. Quantitative data were expressed as mean \pm SD (Standard deviation).

Independent samples t-test was used to compare between two independent groups of normally distributed variables (parametric data). The nonparametric Wilcoxon signed-rank test was used to compare perception and level of activity between faceto-face and online learning. $\mathrm{P}$ value $<0.05$ was considered significant.

\section{RESULTS}

Sociodemographic characteristics among the surveyed students are shown in table 1.
Table (1): Distribution of sociodemographic characteristics among the surveyed students $(n=340)$.

\begin{tabular}{|l|c|}
\hline \multicolumn{1}{|c|}{ Characteristics } & Number (\%) \\
\hline $\begin{array}{l}\text { Age } \\
17-\end{array}$ & $56(16.5 \%)$ \\
\hline $19-$ & $223(65.6 \%)$ \\
\hline $21-23$ & $61(17.9 \%)$ \\
\hline Total & $340(100 \%)$ \\
\hline Mean \pm SD & $\mathbf{( 1 9 . 5 7 \pm 1 . 0 2 )}$ \\
\hline $\begin{array}{l}\text { Gender } \\
\text { Male }\end{array}$ & $131(38.5 \%)$ \\
\hline Female & $209(61.5 \%)$ \\
\hline Total & $340(100 \%)$ \\
\hline $\begin{array}{l}\text { Medical year } \\
1^{\text {st }}\end{array}$ & $87(25.6 \%)$ \\
\hline $2^{\text {nd }}$ & $117(34.4 \%)$ \\
\hline $3^{\text {rd }}$ & $136(40 \%)$ \\
\hline Total & $340(100 \%)$ \\
\hline $\begin{array}{l}\text { Information technology (IT) skills } \\
\text { High }\end{array}$ & $45(13.2 \%)$ \\
\hline Moderate & $265(77.9 \%)$ \\
\hline Low & $30(8.8 \%)$ \\
\hline Total & $340(100 \%)$ \\
\hline $\begin{array}{l}\text { Previous experience in online } \\
\text { learning } \\
\text { Yes }\end{array}$ & $123(36.2 \%)$ \\
\hline No & $217(63.8 \%)$ \\
\hline Total & $340(100 \%)$ \\
\hline
\end{tabular}

Regarding the perceived advantages of online learning, the ability to stay at home had the highest score, followed by learning on your own place while the classes' interactivity was the lowest strength as shown in figure 1 .

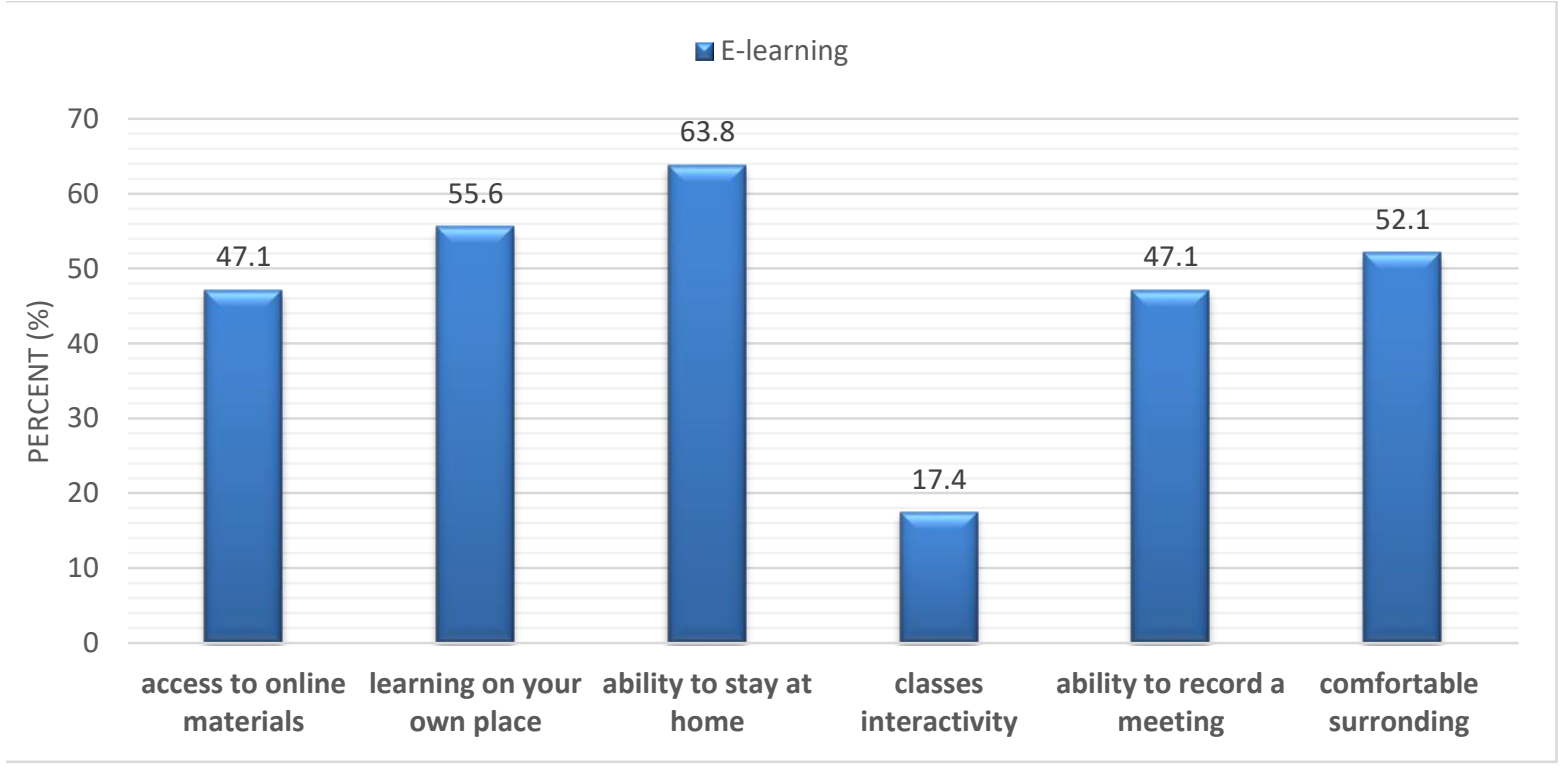

Figure (1): Frequency of responses of students regarding strength points of online learning. 
On the other hand, technical problems were the major disadvantage as mentioned by students followed by lack of interaction with the patients, while poor learning conditions at home was the least selected disadvantage as mentioned by students (Figure 2).

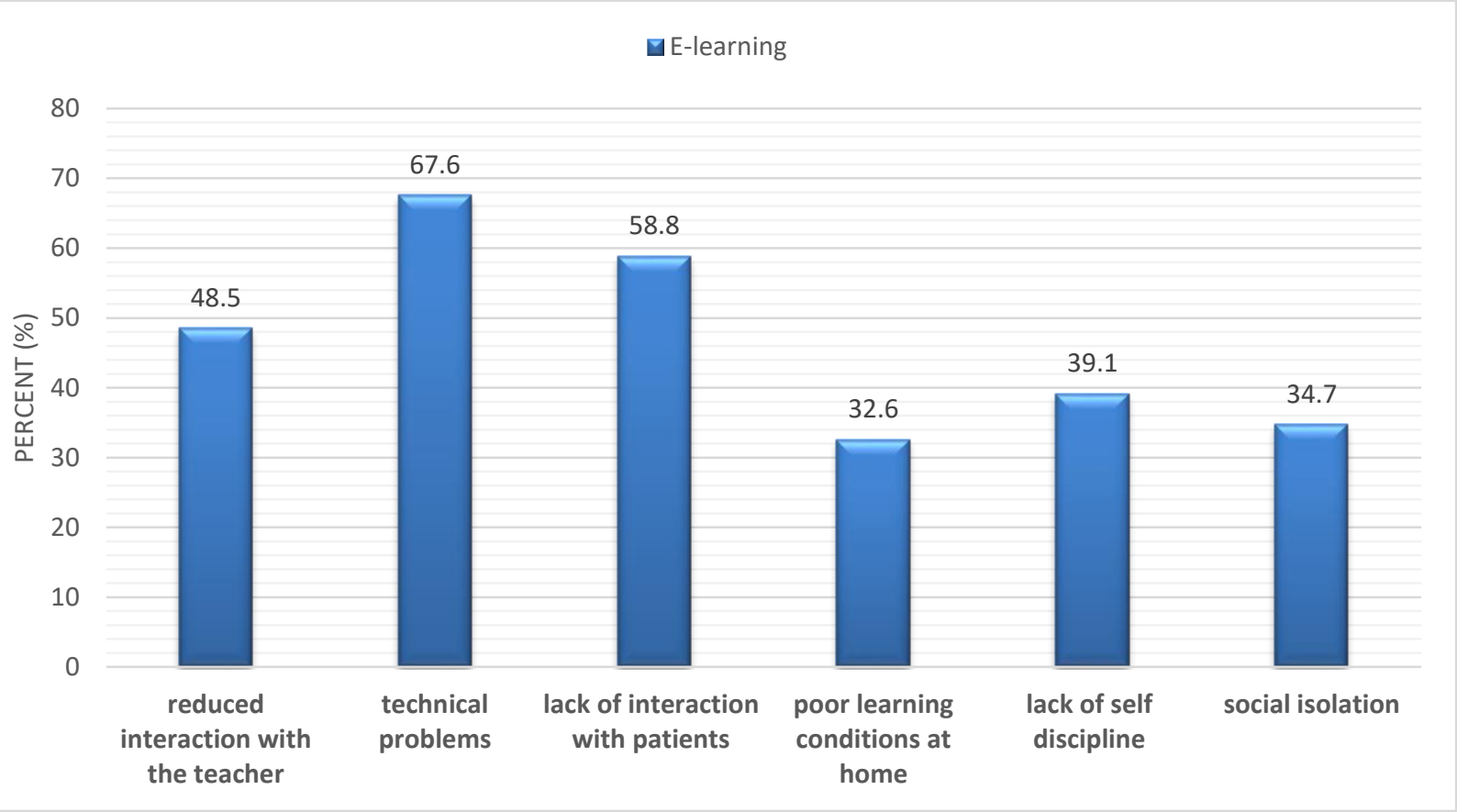

Figure (2): Frequency of responses of students regarding weakness points of online learning.

On comparing between academic and clinical medical students regarding the perceived online learning advantages and disadvantages, a statistically significant difference was detected regarding the online learning advantages (their ability to stay at home) and the disadvantage of online learning (the lack of interaction with patients) (table 2).

Table (2): Comparison between academic and clinical students regarding advantages and disadvantages of online learning $(n=340)$.

\begin{tabular}{|l|c|c|c|c|c|}
\hline \multicolumn{1}{|c|}{$\begin{array}{c}\text { Strength and weakness items of } \\
\text { online learning }\end{array}$} & \multicolumn{2}{c|}{$\begin{array}{c}\text { Clinical } \\
\text { Grade 3 } \\
\text { (n=136) }\end{array}$} & \multicolumn{2}{c|}{$\begin{array}{c}\text { Academic } \\
\text { Grade 1 and 2 } \\
\text { (n=204) }\end{array}$} & \multirow{2}{*}{ P value } \\
\cline { 2 - 5 } & Number & \% & Number & \% & \\
\hline Strength items & 57 & 41.9 & 103 & 50.5 & 0.121 \\
\hline Access to online materials & 73 & 53.7 & 116 & 56.9 & 0.562 \\
\hline Learning on your own pace & 98 & 72.1 & 119 & 58.3 & $\mathbf{0 . 0 0 7 *}$ \\
\hline Ability to stay at home & 19 & 14.0 & 40 & 19.6 & 0.179 \\
\hline Classes interactivity & 60 & 44.1 & 100 & 49.0 & 0.375 \\
\hline Ability to record a meeting & 69 & 50.7 & 108 & 52.9 & 0.69 \\
\hline Comfortable surrounding & 97 & 47.5 & 68 & 50 & 0.658 \\
\hline Weakness items & 130 & 63.7 & 100 & 73.5 & 0.058 \\
\hline Reduced interaction with the teacher & 91 & 44.6 & 109 & 80.1 & $\mathbf{0 . 0 0 0 *}$ \\
\hline Technical problems & 60 & 29.4 & 51 & 37.5 & 0.119 \\
\hline Lack of interactions with patients & 88 & 43.1 & 45 & 33.1 & 0.063 \\
\hline Poor learning conditions at home & 74 & 36.3 & 44 & 32.4 & 0.457 \\
\hline Lack of self-discipline & \multicolumn{5}{|l}{} \\
\hline Social isolation &
\end{tabular}

*P values is significant

A comparison was made between students' perception regarding whether the online learning could replace faceto-face learning or not, and the results showed that there was a statistically significant difference in their opinions as regards knowledge acquisition (Figure 3), the ability to increase clinical skills and social competence. The students also agreed that face-to-face learning was superior to online learning regarding improving the clinical skills and social competence by comparing; the medians of the 2 groups (Figures 4 and 5). 


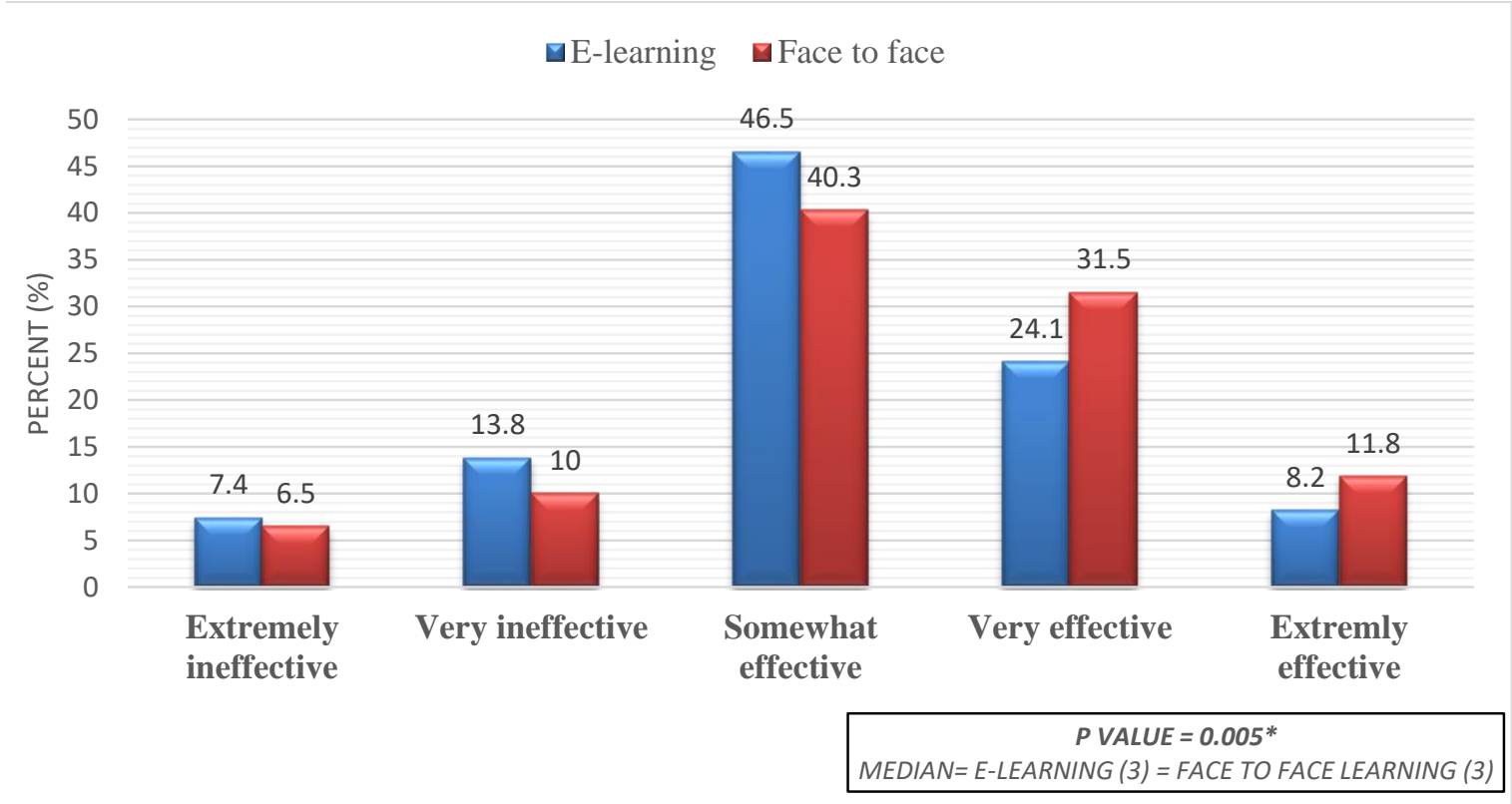

Figure (3): Students' perceived opinion on the ability of face to face and online learning to increase knowledge on a five grade Likert scale.

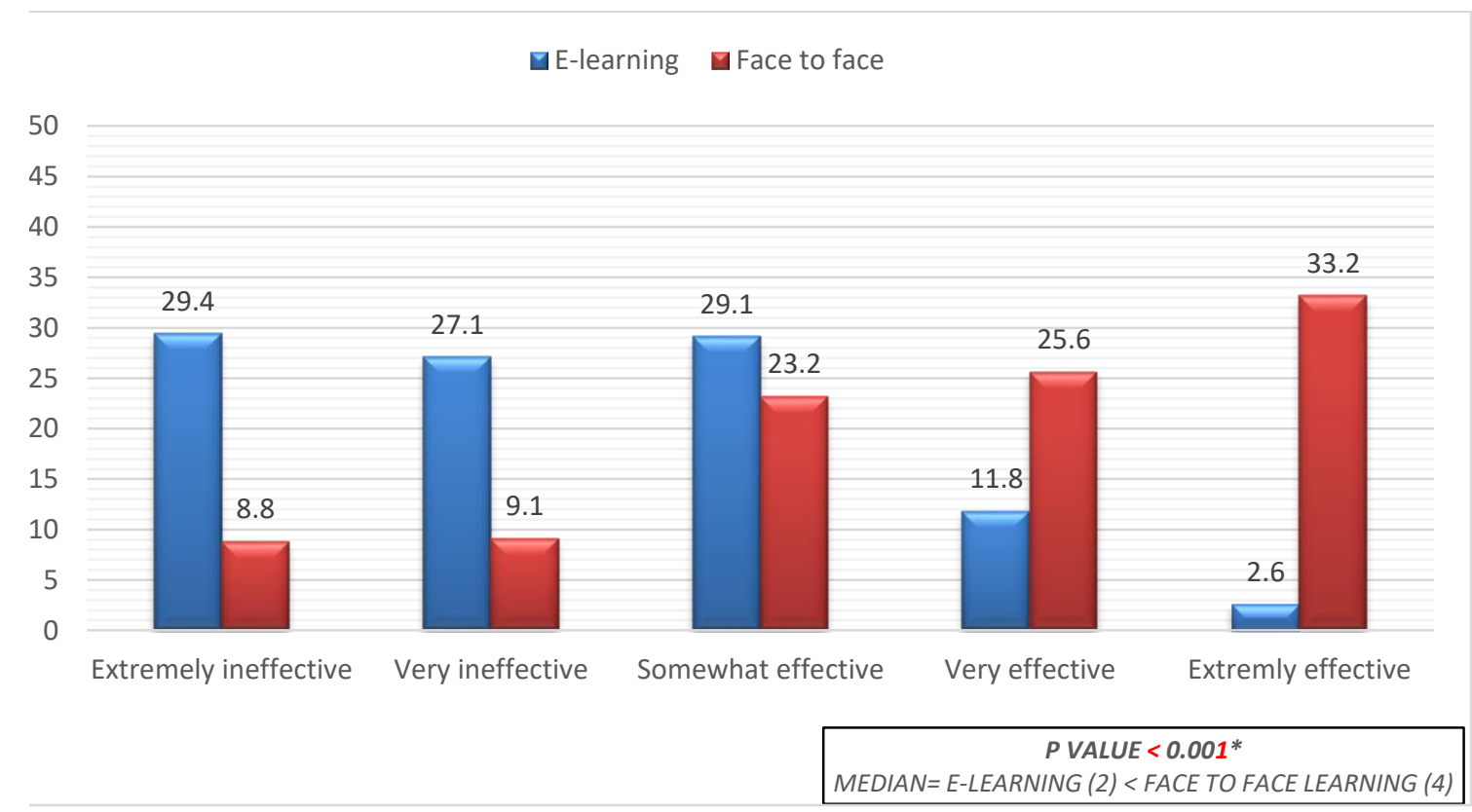

Figure (4): Students' perceived opinion on the ability of face to face and online learning to increase clinical skills. 


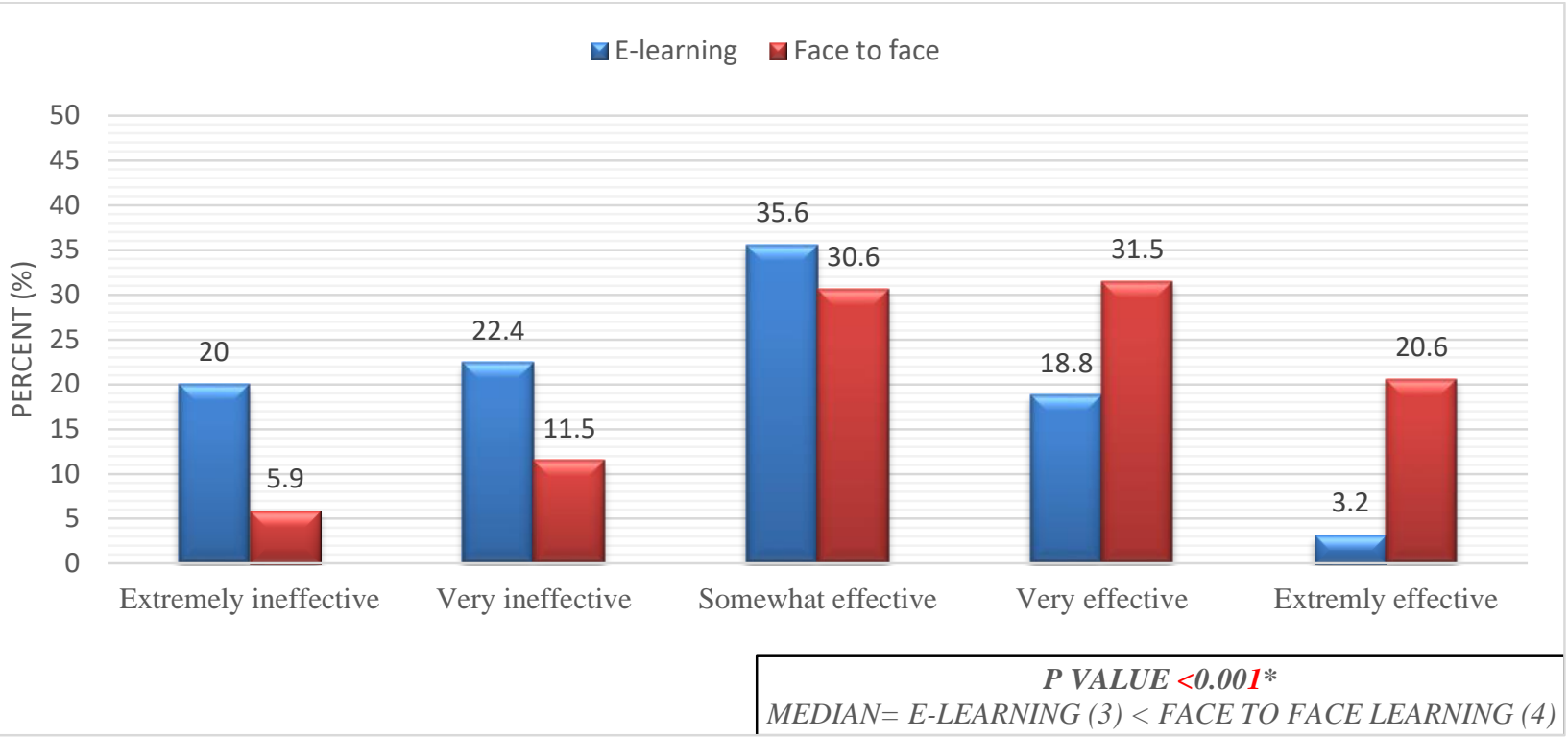

Figure (5): students' perceived opinion on the ability of face to face and online learning to increase social competence on a five grade Likert scale.

When students were asked to rate their level of online activity on a Likert scale from extremely inactive to extremely active during face-to-face vs online learning, they stated that they had lower activity during online classes $(27 \%)$ compared to traditional classes $(44 \%)$ and that difference was also statistically significant $(\mathrm{p}<0.001)$. The most frequent answer was "somewhat active" in both types of learning as shown in figure 6 and 7.

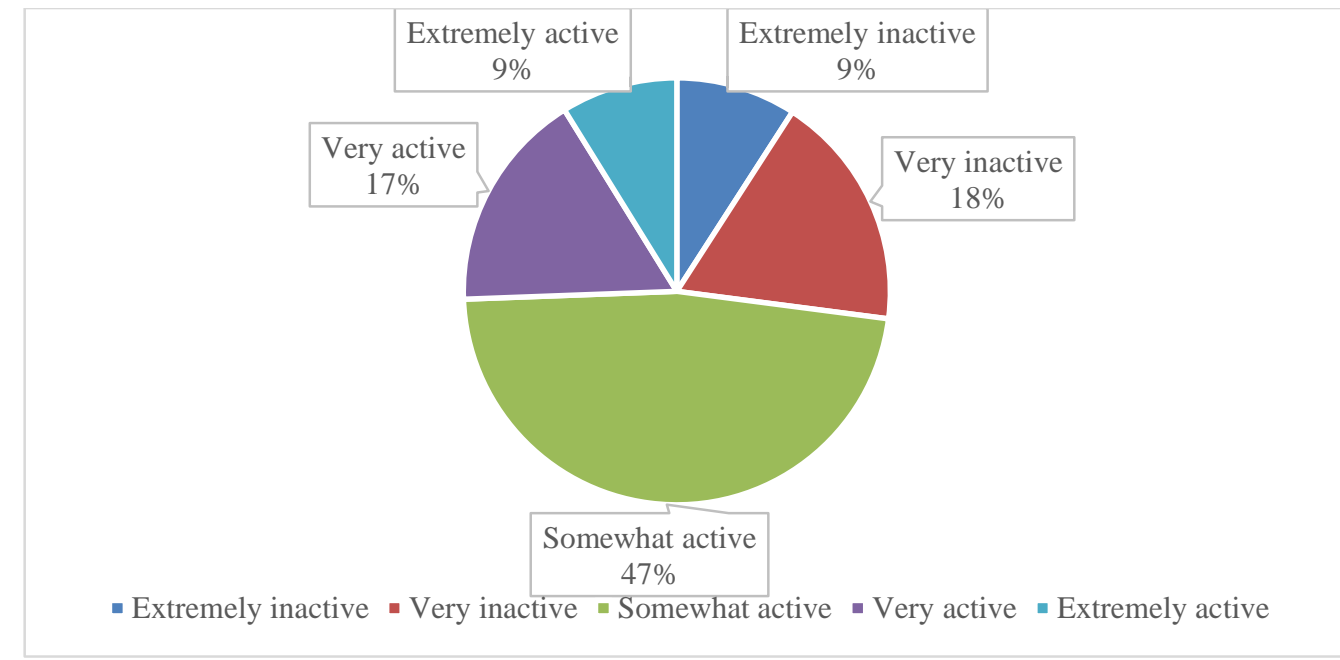

Figure (6): Students' activity during e-learning.

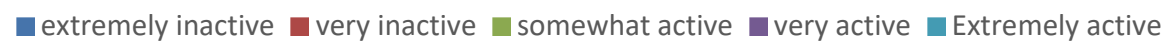

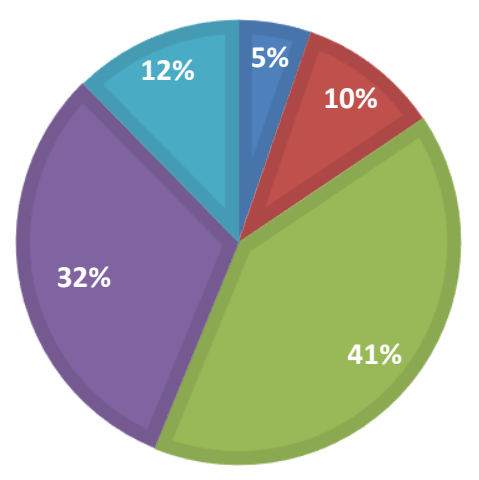

Figure (7): Students' activity during traditional face to face learning. 
By comparing the level of activity between the two groups of students (academic and clinical students), no statistically significant difference was detected as shown in table 3 .

Table (3): Comparison between academic and clinical regarding students' activity during face to face and online learning $(\mathbf{n}=340)$.

\begin{tabular}{|l|c|c|c|c|}
\hline \multirow{2}{*}{$\begin{array}{c}\text { Student activity } \\
\text { responses }\end{array}$} & \multicolumn{2}{c|}{ E-learning } & \multicolumn{2}{c|}{ Traditional face to face learning } \\
\cline { 2 - 6 } & Number & $\%$ & Number & $\%$ \\
\hline Academic(n=204) & 20 & 9.8 & 10 & 4.9 \\
\hline Extremely inactive & 34 & 16.7 & 20 & 9.8 \\
\hline Very inactive & 96 & 47.1 & 80 & 39.2 \\
\hline Somewhat active & 38 & 18.6 & 67 & 32.8 \\
\hline Very active & 16 & 7.8 & 27 & 13.2 \\
\hline Extremely active & 204 & 100.0 & 204 & 100.0 \\
\hline TOTAL & & & & \\
\hline Clinical (n=136) & 11 & 8.1 & 8 & 5.9 \\
\hline Extremely inactive & 27 & 19.9 & 15 & 11 \\
\hline Very inactive & 65 & 47.8 & 58 & 29.4 \\
\hline Somewhat active & 19 & 14 & 40 & 11 \\
\hline Very active & 14 & 10.3 & 15 & 100 \\
\hline Extremely active & 136 & 100 & 136 & \\
\hline TOTAL & & 0.672 & & \\
\hline P value & & & & \\
\hline
\end{tabular}

Concerning the acceptance of online learning, $77 \%$ of students accepted online learning modalities and the most frequent selected response was "somewhat enjoyable" (52\%), and the least frequent response was "extremely enjoyable" (8.5\%). As shown in figure 8.

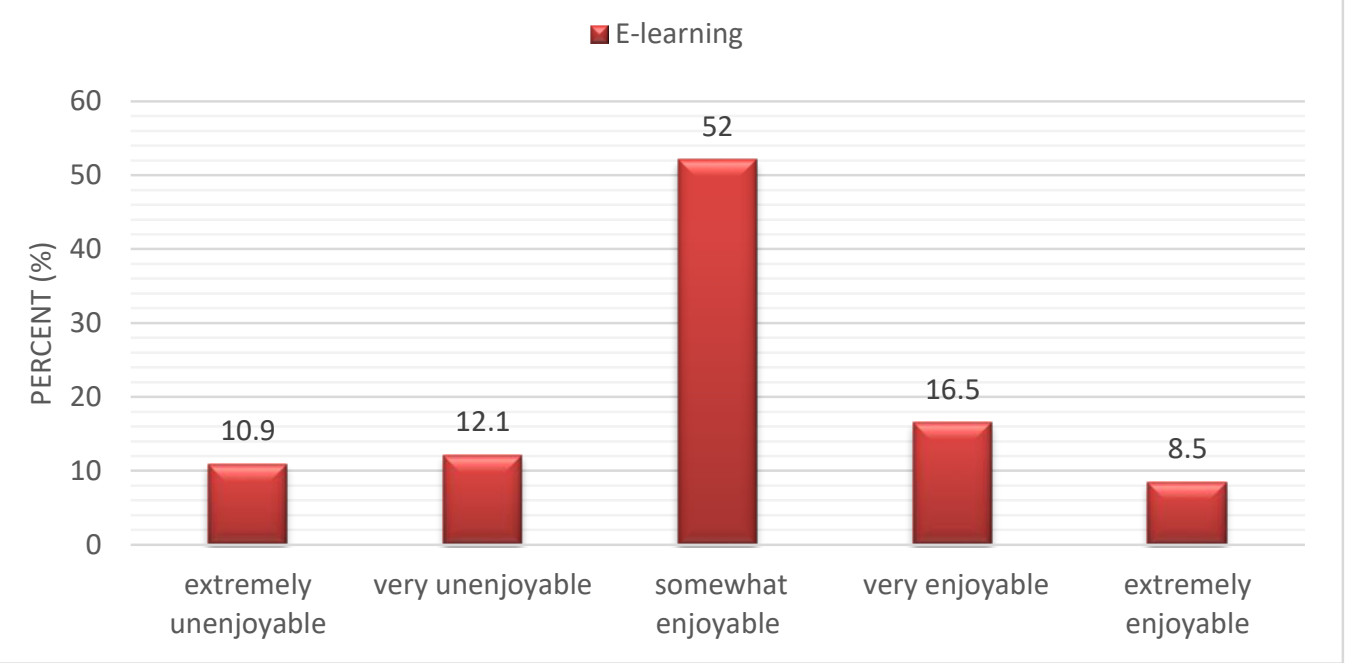

Figure (8): Frequency of responses of students regarding acceptance of online learning.

A comparison was also made between clinical and academic students regarding acceptance of online learning and there was no statistically significant difference between them as shown in table 4 . 
Table (4): Comparison between academic and clinical students regarding how much they enjoyed online learning ( $\mathbf{n}=340)$.

\begin{tabular}{|l|c|c|c|c|}
\hline \multirow{2}{*}{$\begin{array}{c}\text { Enjoying e-learning classes } \\
\text { responses during the pandemic }\end{array}$} & \multicolumn{2}{c|}{$\begin{array}{c}\text { Academic } \\
(\mathbf{n = 2 0 4})\end{array}$} & $\mathbf{2}$ & \multicolumn{2}{c|}{$\begin{array}{c}\text { Clinical } \\
(\mathbf{n = 1 3 6})\end{array}$} \\
\cline { 2 - 5 } & Number & Number & $\%$ \\
\hline Extremely unenjoyable & 23 & 11.3 & 14 & 10.3 \\
\hline Very unenjoyable & 26 & 12.7 & 15 & 11 \\
\hline Somewhat enjoyable & 106 & 52 & 71 & 52.2 \\
\hline Very enjoyable & 35 & 17.2 & 21 & 15.4 \\
\hline Extremely enjoyable & 14 & 6.9 & 15 & 11 \\
\hline TOTAL & 204 & 100.0 & 136 & \\
\hline P value & & & 0.721 & \\
\hline
\end{tabular}

\section{DISCUSSION}

Because of raising of introducing online learning in all medical schools in Egypt, this crosssectional descriptive study was conducted to examine the perceived strengths and weaknesses of online learning among medical students at the FOM-SCU during COVID-19 pandemic. The findings provide evidence for better understanding and improvement of online learning in Egypt.

Our study showed that over $63 \%$ of the respondents hadn't experience of any form of online learning prior to COVID-19 pandemic, also $78 \%$ of the students described their IT information level as moderate and 9\% described their information level as low. This could explain why technical difficulties were selected as the first major disadvantage of online learning in this study. This finding is different from that of Alsoufi et al. ${ }^{\left({ }^{12)}\right.}$ who reported that the majority of his study participants (66.5\%) were very good or proficient in using electronic devices. This detected difference in student readiness for using technology could be attributed to the geographic and cultural characteristics of our study participants as well as to the nature of study before COVID-19 in which the use of technology was limited.

The results also showed that being able to stay safe at home while studying and learning on your own place were rated as the main advantages of online learning among respondents in our survey. This is congruent with the results of Kay and Pasarica ${ }^{(13)}$ and Sindiani et $\boldsymbol{a l} .^{(14)}$ who cited also that among the most important advantages of online learning, according to their study participants, were limited social contact, such as social distancing, and saving money and energy from using university transportations, while the second main advantage was regarded an easier technique of learning.

Despite these advantages and regarding the problems of online learning as perceived by our study participants, our results showed that technical problems was the main problem followed by lack of interaction with the patients. This finding is consistent with other studies Sindiani et al. ${ }^{(14)}$ and Friedman et $a{ }^{(15)}$ who stated that the lack of clinical access for medical students, as well as the need for additional technical support, are the most significant drawbacks for their study participants, due to the necessity of patient exposure, particularly during the clerkship period of medical education.

Regarding students' perception of online learning as compared with face-to-face learning, our study found the face-to-face learning was superior than online learning as perceived by medical students regarding improving the clinical skills and social competence and this is congruent with the finding of Alsoufi et $\boldsymbol{a l} .{ }^{(12)}$ whose participants believed that it is difficult to rely on online learning only due to the numerous challenges faced by learners and teachers. Regarding knowledge acquisition, our study revealed that there was a statistically significant difference between online and face-to-face learning with respect to knowledge acquisition. Studies conducted by Fordis et al. ${ }^{(16)}$ and Yeung et al. ${ }^{(17)}$ found that both interventions (face-to-face small group vs virtual small group) produced similar results. In contrast to the previous result, studies conducted by Raupach $\boldsymbol{e t}$ al. (18) and Subramanian et al. ${ }^{(19)}$ reported that online learning modality demonstrated marked improvement in student learning compared to traditional learning modality. This difference could be explained by the previously mentioned low level of technology use and preparedness among our medical students.

Our results revealed that students' activity in face-to-face learning was better than in online learning and this could be attributed to the new experience with this learning modality as well as the limited interaction with patients and teachers as mentioned before. This to some extent matches what Sindiani et $\boldsymbol{a l} .{ }^{(14)}$ found as their study participants participate less in online learning as they found it less interactive than traditional face-to-face classes.

It's worth mentioning that despite most of our study participants find face-to-face learning superior to online learning (as it improves knowledge acquisition, clinical skills and social competence), the majority of them still find online learning enjoyable. That comes in line with the results of Bacczek et al. ${ }^{(11)}$ and Warnecke and Pearson ${ }^{(20)}$ in which the majority of their respondents rated online learning as enjoyable. 
No significant difference was found between clinical and academic students regarding their perception of online learning and this is also comparable with the findings of Bączek et al. ${ }^{(11)}$ as $73 \%$ of their study participants respondents rated online learning as enjoyable. There was no statistically significant difference between answers given by students in their first three years of studies and those supplied by those who were further along in their education.

\section{CONCLUSION}

This study showed that the ability to stay safe at home and learning on your own place could be considered the prominent advantages of online learning. On the other hand, technical problems and lack of interaction with the patients were the main disadvantage. Our students found face-toface learning is superior to online learning in improving knowledge, clinical skills and social competence. For successful implementation of online learning, well-structured strategy and a more innovative approaches to overcome perceived disadvantages should be considered.

\section{RECOMMENDATIONS}

More research regarding the advantages and disadvantages of online learning should be performed, including an in-depth review of online instruction techniques, step-by-step implementation, and the most effective practices for online course design and instruction. In order to adequately evaluate the efficiency of online learning in the clinical context, future research should include more clinical students.

\section{REFERENCES}

1. Siregar B, Mansyur A, Siregar N (2021): Development of digital book in enhancing students' higher-order thinking skill. Journal of Physics Conference Series, 1819: 1-8.

2. Alnabelsi T, Al-Hussaini A, Owens D (2015): Comparison of traditional face-to-face teaching with synchronous e-learning in otolaryngology emergencies teaching to medical undergraduates: a randomised controlled trial. European Archives of Oto-RhinoLaryngology, 272(3):759-763.

3. Doherty I, McKimm J (2010): E-learning in clinical teaching. British Journal of Hospital Medicine, 71(1):4447.

4. Beynon, M (2007): Computing technology for learning in need of a radical new conception. Educational Technology \& Society, 10(1): 94-106.

5. Anggrawan A, Jihadil Q (2018): Comparative analysis of online e-learning and face to face learning: an experimental study. Third International Conference on Informatics and Computing, 18: 1-4.
6. Bartolic-Zlomislic S, Bates A (1999): Investing in online learning: Potential benefits and limitations. Canadian Journal of Communication, 24(3):349-366.

7. Jang H, Kim K (2014): Use of online clinical videos for clinical skills training for medical students: benefits and challenges. BMC Medical Education, 14(1):1-6.

8. Kentnor H (2015): Distance education and the evolution of online learning in the United States. Curriculum and Teaching Dialogue, 17(1):21-34.

9. Radford A (2011): Learning at a Distance: Undergraduate Enrollment in Distance Education Courses and Degree Programs. Stats in Brief. NCES 2012154. National Center for Education Statistics. https://www.researchgate.net/ publication/234669989_Learning_at_a_Distance_Under graduate_Enrollment_in_Distance_Education_Courses_a nd_Degree_Programs_Stats_in_Brief_NCES_2012-154

10. Abbasi S, Ayoob T, Malik A et al. (2020): Perceptions of students regarding E-learning during Covid-19 at a private medical college. Pak J Med Sci., 36: 57-61.

11.Bączek M, Zagańczyk-Bączek M, Szpringer M et al. (2021): Students' perception of online learning during the COVID-19 pandemic: a survey study of Polish medical students. Medicine, 100 (7): 24821-24825.

12.Alsoufi A, Alsuyihili A, Msherghi A et al. (2020): Impact of the COVID-19 pandemic on medical education: Medical students' knowledge, attitudes, and practices regarding electronic learning. PLoS ONE, 15(11):0242905.

13. Kay D, Pasarica M (2019): Using technology to increase student (and faculty satisfaction with) engagement in medical education. Advances in Physiology Education, 43(3):408-413.

14.Sindiani A, Obeidat N, Alshdaifat E et al. (2020): Distance education during the COVID-19 outbreak: A cross-sectional study among medical students in North of Jordan. Annals of Medicine and Surgery, 59:186-194.

15. Friedman C, Donaldson K, Vantsevich A (2016): Educating medical students in the era of ubiquitous information. Medical Teacher, 38(5):504-509.

16. Fordis M, King J, Ballantyne C et al. (2005): Comparison of the instructional efficacy of internet-based CME with live interactive CME workshops: A randomized controlled trial. JAMA., 294:1043-51.

17. Yeung J, Fung K, Wilson T (2012): Prospective evaluation of a web-based three-dimensional cranial nerve simulation. J Otolaryngol Head Neck, Surg., 41:426-36.

18. Raupach T, Muenscher C, Anders S et al. (2009): Web-based collaborative training of clinical reasoning: A randomized trial. Med Teach., 31: 431-7.

19.Subramanian A, Timberlake M, Mittakanti H et al. (2012): Novel educational approach for medical students: Improved retention rates using interactive medical software compared with traditional lecture-based format. J Surg Educ., 69:253-6.

20. Warnecke E, Pearson S (2011): Medical students' perceptions of using e-learning to enhance the acquisition of consulting skills. Australas Med J., 4:300-7. 